\title{
The Valuation of Infrastructure Index Bonds
}

\author{
Joseph Atta-Mensah \\ Capacity Development Division, United Nations Economic Commission for Africa, Addis Ababa, Ethiopia \\ Email: jattamensah@uneca.org
}

Received 10 August 2015; accepted 2 November 2015; published 5 November 2015

Copyright (C) 2015 by author and Scientific Research Publishing Inc.

This work is licensed under the Creative Commons Attribution International License (CC BY).

http://creativecommons.org/licenses/by/4.0/

(c) (i) Open Access

\begin{abstract}
The paper examines a potential role of financing Africa's infrastructure projects, particularly in Africa, with bonds indexed to the project. Using option-pricing techniques, the author shows that an infrastructure indexed bond is equivalent to a regular bond and a short position on a European put option. The results of the paper suggest that the value of the infrastructure indexed bond increases monotonically as the value of the project it is financing rises. In addition, the market value of the infrastructure-indexed bonds falls as the value of the project becomes more volatile. The rise in the dividend rate on the project is observed to have an adverse effect on the value of infrastructure-indexed bonds.
\end{abstract}

\section{Keywords}

\section{Indexed-Linked Bonds and Infrastructure}

\section{Introduction}

The lack of adequate infrastructure in Africa is hampering the continent's economic performance as good and strong infrastructure does support the sustainable economic growth and wealth generation. Moreover, in this age of globalization, industries depend more and more on modern and efficient local infrastructure to enhance low operational costs and high quality service.

In Africa and other developing countries, the building and operation of infrastructure are undertaken by governments. However, this trend is changing as the private sector is attempting to get into the financing and operation of infrastructure facilities. The demand for private investment has arisen as a result of: 1) the lack of government financial resources; 2) decrease in Overseas Development Assistance (ODA) for infrastructure projects; and 3) the strong demand for new infrastructure development. Governments of the developing countries are paying attention and are slowly expanding the role of the private sector to implement their infrastructure programmes.

To enhance the participation of the private sector in the financing of infrastructure development projects, it requires that a sound financing framework should be established. Vehicles that can be used to support the fi- 
nancing of projects are the global capital markets. These markets have the depth, maturity, size and the capability of handling complex shocks and therefore have the potential of funding infrastructure projects.

This paper calls on governments to issue infrastructure bonds, which is a potential means of financing Africa's infrastructure. The paper argues that these bonds can be raised by African countries on global capital markets. Infrastructure development requires high capital infusion and specific investments, and factors that deter the private sector to commit long-term capital. However, by raising the capital required to finance the infrastructure projects from the bond market, financial risks become diversified so as to ensure allocative efficiency.

The paper is organized as follows: section 2 provides a brief review on the state of Africa's infrastructure; section 3 provides an overview on the traditional ways of financing infrastructure; section 4 makes a case for innovative financing arrangements needed in the financing of Africa's infrastructure needs; section 5 discusses the pricing of infrastructure bonds; concluding remarks are made in section 6.

\section{The State of Africa's Infrastructure}

Compared to world standards, Africa's infrastructure transport network is generally very weak. The main mode of transportation is by road, accounting for 90 per cent of urban transport. Yet of the 2 million kilometres of Africa's road networks only about 28 per cent are paved. Moreover, the road density is extremely low, estimated at about 7 kilometres per 100 square kilometres. The railway connectivity in Africa is also very weak, particularly in central and west Africa. For a continent of size 30 million square kilometres, the rail network accounts for only 89,380 kilometres, translating into 3 kilometres of rail lines per 1000. Most of Africa's international trade depends on maritime transport. Yet a great number of the ports are below international standards. The merchant fleet are also very old, with an average age of 19 years as opposed to a world average of 14 years. Africa's air transport networks also need to be brought to world standards. It is probably easier to fly from an African country to Europe or the US than to fly within Africa. Perhaps the adoption and the implementation of the Yamoussoukro Decision in 2000 could expiate the process of opening up the skies of the continent.

The challenges faced on the continent in the operation of transport include cumbersome customs and administrative procedures, roadblocks, inefficient operators, and inappropriate vehicles, factors contributing to high transportation costs. Transport costs remain very high in Africa, particularly for landlocked countries because of poor infrastructure and weak institutions. The strengthening of the transport system of the continent would not be an easy chore. It would require the total commitment of member countries of the African Union. It would require massive financial support. This calls for a "paradigm shift" from the traditional sources of funds for infrastructure. The leadership may therefore have to turn to other non-traditional methods that would attract private investment in infrastructure. The idea of public-private-partnership projects (PPP) should therefore be embraced by the African leadership.

Although there have been some improvements, communication systems in Africa remain very weak. To strengthen regional integration efforts there is the strong need for African countries to modernize existing ICTs. The strengthened ICTs would contribute to growth in trade and financial services as well as reduce the cost of information and linking communities with each other. In recent years the communications network on the continent has improved significantly, attracting greater investment from local and foreign investors. In most parts of the continent, the growth in fixed line telephone connectivity and mobile telephones services have risen remarkably. Internet use by the population is also up. Despite the improvements made in this field, compared to the past, more needs to be done if Africa is to bridge the digital divide. It is essential the strengthening of the telecommunication sector of the continent would require the convergence of national policies. This would require: the harmonization of market structures; the creation of conditions that ensure the interconnection among operators in different countries; the harmonization of tariff principles; and reducing the costs of telecommunications services.

Africa is endowed with a lot of energy resources - oil, coal, hydroelectricity, natural gas, and biomass and other renewable energy sources. Yet these have not been efficiently tapped or underdeveloped. Those that are developed are often located far from the demand centres. The infrastructure-gas pipelines and electricity transmission and distribution networks - needed to move the supply to consumers remain very weak. To ensure a sufficient, sustainable supply of commercial energy it is important the infrastructure is strengthened.

Africa is increasing their efforts to promote regional power pools and interconnected electricity grids and master plans for regional power development and environmentally benign power sources. Oil and gas pipelines 
are also being connected from supply points to consumers. These include the Trans-Mediterranean Gas Pipeline linking Algeria to Italy through Tunisia; the Maghreb and Europe Gas Pipeline linking Algeria to Spain through Morocco; the West African Gas Pipeline supplies Benin, Ghana, and Togo with natural gas from Nigeria; the Mozambique-South Africa Natural Gas Project among others. The regional economic communities continue to promote regional cooperation in the development of hydropower resources. The RECs efforts have contributed to countries jointly developing several hydro power generating facilities. Although significant progress has been made in strengthening Africa's energy infrastructure, substantial investments are still required in order to bring the infrastructure to world standards. Going forward, there is the strong need for the leadership of the continent to encourage cross-border energy trade, the development of regional power pools, harmonization of regulatory policies and investment codes, and engaging in capacity-building activities.

\section{Traditional Forms of Financing Infrastructure in Africa}

Before the paper argues that Africa's infrastructure development can be financed with infrastructure indexed bonds, it is important that we present a brief discussion on the current form of financing used by African countries. This is important in a number of ways because it contributes to the motivation of the paper. In addition, it allows the recommendation of this paper to be compared with existing methods used by developing countries, particularly those in Africa, to deal with their infrastructure development needs.

Traditionally, all of the developing economies, including African countries, rely mainly on the World Bank in the financing of infrastructure. The forms of financing offered by the World Bank to the countries include loans, guarantees, equity investments, and political risk insurance. The agencies of the Bank responsible for financially aiding the African countries are: the International Bank for Reconstruction and Development (IBRD) and the International Development Association (IDA), together referred to as the World Bank; the International Finance Corporation (IFC); and the Multilateral Investment Guarantee Agency (MIGA). What are the functions of these agencies and what contractual arrangements do they reach with developing countries in the development of their infrastructure?

\section{Loans and Guarantees by IBRD}

The World Bank, through IBRD and IDA, finances both public and private sector projects. IBRD supports middle-income developing countries while the IDA provides assistance to least developed countries. The financial assistance given by the World Bank (IBRD and IDA) is general in the form of loans. However, IBRD has provided limited forms of guarantees to support infrastructure projects undertaken by some of countries. Governments sometimes use the IBRD and IDA loans to finance equity, guarantees, and other forms of financial support. In the next part of this section we provide examples to explain how the World Bank supports infrastructure projects in developing countries.

IBRD charges interests on its loans at a few basis points higher than those charged to AAA-rated bonds. The loans could be contracted in two forms. One form is where, for example, IBRD lends directly to a consortium constructing a super highway and, as required by IBRD's Articles of Agreement, the loan is guaranteed by the host country to IBRD. The second contractual arrangement would be the case where IBRD would lend directly to the host country, which in turn would loan to a public or private company. This contractual arrangement is therefore made up of a loan agreement between IBRD and the host country and a subsidiary loan agreement between the host country and the public or private company.

The guarantees offered by IBRD for private lending takes two forms: a partial risk guarantee protecting lenders against payment defaults arising from breaches of sovereign contractual undertakings to a project, and a partial credit guarantee covering certain debt service payments against all risks, typically for later maturities. IBRD's Articles of Agreement requires that all its guarantees are counter-guaranteed by the host country.

The provision of a partial risk guarantee by IBRD for private lending takes the following structure: 1) loans by commercial lenders; 2) host country contractual undertakings to the public or private company that would support the infrastructure project; 3) an IBRD partial risk guaranteeing loans against private investors debt service defaults arising from host country breaches of contract; and a host country counter-guarantee to IBRD.

To further explain the partial risk guarantee let us take a consortium of public-private-partnership in the construction of a super highway in a developing country and IBRD agrees to provide partial risk guarantees for the project. The host country would then undertake to make compensatory payments to the consortium should there be a specified contractual defaults by the sub-contractors of the project. The IBRD guarantee protects lenders to 
the consortium against debt service defaults resulting from the host country's breach of this obligation. The host country in this case should have a counter-guarantee to IBRD.

Alternatively, IBRD could provide a partial credit guarantee to the commercial lenders to protect them against default by the consortium on debt service payments. This structure would involve the same basic agreements as the partial risk guarantee, but would not require contractual undertakings from the host country to the consortium.

\section{IBRD financing in IDA countries}

Generally, IBRD does not finance projects in poorer developing countries. This is because these countries are not in a position to pay IBRD's market lending rates as their credit worthiness is very low. These countries receive only concessionary IDA lending (referred to as IDA-only countries). In exceptional cases, IBRD has offered loans for certain projects in IDA-only countries that generate substantial foreign exchange revenues (referred to as enclave projects). In addition, these projects typically include an offshore escrow account for debt service payments and a guarantee to IBRD from a creditworthy third party, such as the project's private shareholders. Enclave projects could also be eligible for an IBRD guarantee.

\section{IDA Loans}

IDA offers fairly favourable loans to poor developing nations. These loans are made generally on very good concessional terms, with maturities of thirty-five to forty years and a 0.75 percent interest rate. IDA loans to a host country, which in turn lends the funds to the company responsible for developing the infrastructure project. In the example used in the previous section, IDA would support the development of the super highway by entering into a loan agreement with the host country. The host country would then loan the funds to the Consortium backed by a project agreement between the Consortium and IDA.

\section{Equity Financing}

IBRD and IDA do not invest directly in infrastructure projects of developing countries. In other words either of the two agencies holds equity stakes in projects carried out in the countries they loan to. However, either of the agencies could provide loans or credits to a country to finance its equity investment in an infrastructure project. In the example being used in this Section, the host country could obtain an IBRD loan or an IDA credit to finance an equity stake in the Consortium developing the super highway. In this case, IBRD would have a loan agreement with the host country. The host country would then have a subsidiary loan agreement with a parastatal company which would then use the funds to have an equity stake in the Consortium.

\section{Financing guarantees and debt refinancing}

IBRD and IDA also provide loans to countries to finance guarantees offered by host countries to investors who are undertaking infrastructure development. For example, a country could finance a loan guarantee issued by an independent guarantor mandated by the government with a loan from IBRD or IDA. The structure of such an arrangement would involve IBRD or IDA providing a loan to the host country. The host country would then use this funds, through a parastatal agency such a financial intermediary, to provide guarantees to commercial lenders (banks) who have loan agreements with the project developers (the Consortium in our example).

Financial intermediaries, investment funds, and facilities

In some cases IBRD and IDA do lend to a host country to finance financial intermediaries or an investment fund or other facility that would provide loans, equity, guarantees, take-out financing, or other financial support for special projects. An example is where IBRD provides loan to a host country to finance a government-sponsored fund that lends to selected private sector infrastructure projects.

\section{IFC's loans, loan syndication, equity, and quasi equity}

The IFC generally offers loans or holds equity and quasi equity investments in private ventures only. Unlike the World Bank, IFC financing requires no direct government guarantees of repayment. Loans made by the IFC attract market interest rates. To hedge against currency transfer and other political risks to lenders, the IFC provides an extensive loan syndication program (known as B-loans) by extending its lender-of-record umbrella to participating banks. B-loans are always coupled with loans funded from IFC's own resources (A-loans). In the construction of the super highway example, IFC could have an equity stake in the Consortium with an A-loan and a syndicated B-loan. At the same time it could choose to have participation agreements with syndicated commercial lenders who are providing loans to the Consortium.

\section{MIGA's political risk insurance}

MIGA provides guarantee for foreign equity and related debt investments to cover unforeseen political risk. The coverage is for war and civil disturbance, expropriation, and currency transfer risks. MIGA also offers 
guarantees for breach of contracts which the host country prevents claimants to seek relief through judicial courts. In our example, MIGA insurance would be provided to the Consortium developing the super highway.

\section{Group support}

The World Bank also provides financial assistance to infrastructure projects supported by all its agencies so as to encourage foreign direct investment (FDIs). In the example of the construction of the highways, the Consortium could receive support from the World Bank through IFC equity (A- and B-loans), MIGA political risk insurance, and an IBRD partial risk guarantee.

\section{Making the Case for Innovative Financing Mechanism for Infrastructure}

One of the aims of this paper is to suggest that African countries consider issuing bonds indexed to infrastructure projects as a way to complementing the sources of funds allocated to infrastructure projects. It is well known that Africa needs massive investments in infrastructure in order to catch up with world standards. The capacities of the World Bank, European Union, the African Development Bank and other multilateral and bilateral development partners would not be enough to support the infrastructure needs of the continent. It was about time that Africa considered more innovative mechanism for financing its infrastructure needs, relying on its own resources.

In Africa, governments or the public are traditionally responsible for the construction and operation of infrastructure facilities. However, the provision and management of infrastructure in most developing countries, including those in Africa, have not been very impressive. This has led to an increase in the demand for private sector intervention in the provision of infrastructure on the continent. The limited financial resources of African governments are one the reason for their inability to provide adequate infrastructure. Furthermore infrastructure competes with other sectors, such agriculture, health and education, for the attention of managers of the government purse. Moreover, infrastructure is heavily subsidized by the governments as services are priced below costs, putting tremendous strain of the budget of governments.

Despite the worsening budget conditions of African governments, the demand for infrastructure is on the rise as Africa try to integrate into the global economy. The demand for the infrastructure and services in the rural Africa is also on the rise. Compounding the woes of Africa is the decline in concessional aid (both bilateral and multilateral) for infrastructure projects. Given that most African countries depend on ODA's for infrastructure developments, the decline would hamper efforts to improve infrastructure on the continent. The shortfall in the financing of infrastructure plus the inefficiency in the operation of infrastructure services in Africa calls for new and innovative ways of addressing the problem. The participation of the private sector is part of the solution. It has been argued that the private sector involvement in the provision of infrastructure would improve efficiency in the operation of the service.

There several mechanisms in which the private could be involved in the development of infrastructure in Africa. These mechanisms could give different roles to public and private institutions in areas such as ownership, operation, management, financing, risk sharing, duration, and contractual management. It must be pointed out that the participation of the private sector in the development of Africa's weak infrastructure does not guarantee instant success. The private sector could fail if the proper enabling environment is not created. Steps and strategies that could be taken could include, developing sound regulatory regimes and strengthening regulatory capacity; improving the efficiency and accountability of service provision through sound contract design; ensuring the transparency of privatization or award processes; developing local financial markets; and reducing transaction and bidding costs of infrastructure projects, which are typically quite high.

One source of finance that could support infrastructure development could be through the issuance of infrastructure-indexed bonds. This bond is different from a regular bond as its value is linked to the market value of the investment project. Given that the fall in the value of infrastructure increases the probability of default, investors could be attracted by setting coupon payments on the infrastructure indexed bonds to be higher than those paid to bearers of a regular bond. Who would hold the indexed bonds? Most African governments carry out pension or retirement schemes for its employers. These pensions are idling around and not properly managed. Given the size of the investments needed in the development of the infrastructure a suggestion is for part of this pension is invested in the infrastructure indexed bonds. In addition the African diaspora could be encouraged to invest in these bonds as well. In the next section we propose a method of pricing these bonds.

\section{The Valuation of Infrastructure-Indexed Bonds}

Option pricing techniques are very flexible such that they can easily be used in the valuation of most financial 
instruments. In this section, we use the technique to suggest a pricing formula for the infrastructure bond. It also assumed under the contractual framework that the bond-holders would take over the project if the borrower defaults on the payment. Although the future value of the project is not known, we assume that all parties have full knowledge of the initial market value of the project. Under this assumption, the borrower will rationally default at any time during the contract period if the market value of the project is less than the outstanding balance of the infrastructure-indexed bond.

To finance the infrastructure project in some part of an African country or in a region of the continent, we assume that the government of the country in question or a regional economic community would invite private sector participation in the financing of the project through the issue of bonds linked to the project. Let us assume that the face value of the Bond is $F$ and the market of value of the project is $V$, then the expected value of the infrastructure-indexed bond at the end of the contract is:

$$
\operatorname{Min}[F, V]
$$

We make a further assumption that embedded in $F$ are all the necessary costs incurred by the bond-holders upon defaulting of the contract. ${ }^{1}$ In addition to the above assumption, we shall make the usual assumptions for modelling continuous-time asset-pricing models: 1 ) assets are traded in a frictionless or perfect market, where there are no taxes, transactions costs, or short sale restrictions, and all assets are perfectly divisible; 2) trading of assets is done continuously; and 3) the value of the project follows a continuous-time diffusion process. For reasons of parsimony, the interest rates are also assumed to be deterministic. Lastly, we assume that lenders and borrowers have the same information on, and identical beliefs in, the prospects for the project. Both therefore agree on the diffusion process followed by the value of the project. Let $V(t)$ be the market value of the project and its stochastic process be of the form:

$$
\frac{\mathrm{d} V}{V}=\left(\propto_{v}-\frac{\delta}{V}\right) \mathrm{d} t+\sigma_{v} \mathrm{~d} z_{v}
$$

where $\mathrm{d} z_{v}$ is a standard Brownian motion, with mean zero and variance $\mathrm{d} t$. In Equation (2), it is assumed that the project pays out dividends at a constant rate, $d$. The diffusion part (the second part on the right-hand side) of Equation (2) makes the instantaneous rate of appreciation of the project uncertain. Hence, the expected rate of appreciation of the project is $\left(\propto_{v}-\frac{\delta}{V}\right)$.

\section{Pricing formula of the Infrastructure Indexed Bond}

Since the bond is indexed to the market value of the infrastructure project then the market value of the bond at any given time is $B(V, t)$. Using the Ito's lemma, the drift and the diffusion of the bond could be expressed as:

$$
\mathrm{d} B=B_{v} \mathrm{~d} V+\frac{1}{2} B_{v v}(\mathrm{~d} V)^{2}+B_{t} \mathrm{~d} t
$$

which upon simplifying, yields:

$$
\frac{\mathrm{d} B}{B}=\alpha_{b} \mathrm{~d} t+\sigma_{b} \mathrm{~d} z_{b}
$$

where

$$
\begin{gathered}
\alpha_{b}=\frac{\left[\frac{1}{2} \sigma_{v}^{2} V^{2} B_{v v}+\left(\alpha_{v}-\frac{\delta}{V}\right) V B_{v}+B_{t}+c\right]}{B} \\
\sigma_{b}=\frac{\sigma_{v} V B_{v}}{B}
\end{gathered}
$$

$c$ is the instantaneous coupon rate paid to bond holders.

Proposition 1: Based on the assumptions and the framework proposed the partial differential equation governing the infrastructure-indexed bond, which pays an instantaneous coupon rate of $c$ is

${ }^{1}$ These costs may include bankruptcy, legal, and reputation costs. 


$$
\frac{1}{2} \sigma_{v}^{2} V^{2} B_{v v}+(r V-\delta) B_{v}+B_{t}-r B+c=0
$$

Proof:

Standard arbitrage arguments common in the options-pricing literature are employed for the proof.

Proposition 2: The present value of the bond under the set of assumptions is:

$$
B(V, \tau)=\frac{c}{r}\left(1-\mathrm{e}^{-r \tau}\right)+F \mathrm{e}^{-r \tau}-P(V, F, \tau)
$$

$P(V, F, t)$ is a European put option on the infrastructure project, $V$, with constant dividend $\delta V$ and an exercise price equal to the principal payment, $F$. The value of the put option is:

$$
P(V, F, \tau)=F \mathrm{e}^{-r \tau} N\left(d_{1}\right)-V \mathrm{e}^{-\delta \tau} N\left(d_{2}\right)
$$

where

$$
\begin{aligned}
& d_{1}=\frac{\log \left(\frac{F}{V}\right)+\left((\delta-r)+\frac{1}{2} \sigma_{v}^{2}\right) \tau}{\sigma_{v} \sqrt{\tau}} \\
& d_{2}=d_{1}-\sigma_{v} \sqrt{\tau}
\end{aligned}
$$

and $N($.$) is the cumulative normal distribution function.$

Proof:

Rewrite Equation (1) as:

$$
\operatorname{Min}[F, V]=F-\max [0, F-V]
$$

What Equation (9) says that the value of the infrastructure-indexed bond is equivalent to a regular bond (with face value of $F$ ) and a short position on a European put option on the project, with the time left to maturity $\tau$ ( $T$ $t$ ) and the strike price equal to the final payment of the infrastructure-indexed bond, which by our assumption is the principal, $F$. The first term of Equation (8) is the present value of the stream of coupon payments that would accrue to the bond holder over the life of the bond. The second term is the present value of the face value of the bond. The put option value follows from [1]-[4]. Lastly, by performing the relevant differentiations, we find that Equations (8)-(10) correspond to Equation (7), the stochastic partial differential. ${ }^{2}$

Propositions 1 and 2 indicate that the value of the infrastructure-indexed bond is a function of the value of the project, creating an incentive needed to ensure that the project is carried through. In the next section we perform simple comparative statics to examine how the factors underlying the pricing formula impact on the infrastructure indexed bonds.

\section{Properties of the infrastructure-indexed bonds}

This section focuses on assessing factors that impact on the value of the indexed-bonds. This is carried out by studying the influence of key parameters on the pricing formula derived in the last section for the infrastructure indexed bonds.

Proposition 3: The value of the infrastructure indexed bond increases monotonically as the value of the project it is financing rises.

Proof:

Differentiating Equation (8) with respect to $V$ :

$$
\frac{\partial B}{\partial V}=-\frac{\partial P}{\partial V}=-\left(-\mathrm{e}^{-\delta \tau} N\left(d_{2}\right)\right) \geq 0
$$

Remarks: The result corroborates conventional wisdom, which suggests that the higher the value of the project, the greater the size of the infrastructure-indexed bond, given the same level of project risk. An explanation is that as the market value of the project that the indexed bond is being used to finance increases, the probability that the put call embedded in the bond finishes out-of-money also increases, contributing to the rise in the value of the bond. Vice-versa the fall in the market value of the project reduces the value of the indexed bond, reduc-

${ }^{2}$ See [5]-[7] for further discussion on the pricing of financial assets. 
ing the debt burden of the borrower. This result is very important because unlike the traditional bond whose value remains the same regardless of the value of the project, in the case of the indexed bonds its value is directly linked to the market value of the project.

Proposition 4: The market value of the infrastructure-indexed bonds falls as the value of the project becomes more volatile.

Proof:

Differentiating Equation (8) with respect to the variance of $V, \sigma_{v}$, yields:

$$
\frac{\partial B}{\partial \sigma_{v}}=-\frac{\partial P}{\partial \sigma_{v}}=-\left(\sqrt{\tau} \mathrm{Ve}^{-\delta \tau} N^{\prime}\left(d_{2}\right)\right) \leq 0
$$

Remarks: The result shows that the risk-averse investors will be very reluctant to hold the infrastructure-indexed bonds if the project is very risky (measured by the volatility of the market value of the project). In a sense this imposes discipline on borrowers and prevents them from taking up risky ventures as investors are less likely to "bank roll" them. Technically, the rise in the volatility of the market value of the project increases the value of the put option embedded in the indexed bond. This is because a put call has no downside risk, since the value of the put is zero irrespective of how far it finishes out of the money. What the increase in the volatility of the market value of project does is to increase the likelihood that the put option would finish in the money.

Proposition 5: The value of the infrastructure-indexed bonds rises monotonically with the face value, F, of the bond.

Proof:

Differentiating Equation (8) with respect to $F$ yields:

$$
\frac{\partial B}{\partial F}=\mathrm{e}^{-r \tau}\left(1-N\left(d_{1}\right)\right) \geq 0
$$

since $0 \leq N\left(d_{1}\right) \leq 1$.

Remarks: To explain the results one needs to recall that technically the indexed bond could be decomposed into a regular bond and short position on a put option on the project with a strike equal to the face value of the regular bond. Hence an increase in the principal of the indexed bonds leads to an increase in the value of the regular bond component of the indexed bond and at the same time an increase in the short position of the put option. On net, the indexed bond rises in value because the regular bond dominates the put option. Intuitively, the results mean that investors would be attracted to the indexed bonds if its face value should rise.

Proposition 6: A tightening of monetary policy has a negative impact on the market value of an infrastructure-indexed bond.

Proof:

Differentiating Equation (8) with respect to the interest rate, $r$, gives:

$$
\frac{\partial B}{\partial r}=-\frac{c}{r^{2}}\left[1-(1+r \tau) \mathrm{e}^{-r \tau}\right]-\tau F \mathrm{e}^{-r \tau}\left(1-N\left(d_{1}\right)\right) \leq 0
$$

since $0 \leq N\left(d_{1}\right) \leq 1$ and given that $r$ and $\tau$ are non-negative we should expect $\left[1-(1+r \tau) \mathrm{e}^{-r \tau}\right] \geq 0$.

Remarks: Intuitively, interest rates bear a negative relationship with the price of a financial asset. That is why asset prices fall with the tightening of monetary policy. The result shows that the increase in the interest rates leads to a decline in the market value of infrastructure-indexed bonds. The results can be explained by the fact that the rise in interest rates reduces the present values of the bond component of the infrastructure-indexed bond and the exercise price of the put option. These factors combine to depress the market value of the infrastructure-indexed bond.

Proposition 7: The rise in the dividend rate on the project has an adverse effect on the value of infrastructure-indexed bonds.

Proof:

Differentiating Equation (8) with respect to the dividend rate, $\delta$ gives:

$$
\frac{\partial B}{\partial \delta}=-\tau \operatorname{Ve}^{-\delta \tau} N\left(d_{2}\right) \leq 0
$$

Remarks: An intuitive explanation of this result is that the rise in the dividend makes ownership in the project 
more attractive than bearing the indexed bonds as a result the fall in the value of the indexed bonds. A technical explanation is that the rise in the dividend rate increases the value of the put option component embedded in the index bonds. Since the contribution of the put option to the value of the indexed bond is negative a rise in the dividend rate on the value of the indexed bond is negative.

Proposition 8: The term-to-maturity date has an ambiguous effect on the value of infrastructure-indexed bonds.

Proof:

Differentiating Equation (8) with respect to the term left to maturity, $t$, and simplifying:

$$
\frac{\partial B}{\partial \tau}=c \mathrm{e}^{-r \tau}-r F \mathrm{e}^{-r \tau}\left(1-N\left(d_{1}\right)\right)-V \delta \mathrm{e}^{-\delta \tau} N\left(d_{2}\right)+\frac{\sigma_{v}}{2 \sqrt{\tau}} F \mathrm{e}^{-r \tau} N^{\prime}\left(d_{1}\right)
$$

Clearly, the sign for Equation (16) is indeterminate.

Remarks: This result demonstrates that investors are indifferent between holding short- and long-term infrastructure-indexed bonds.

\section{Conclusions}

This paper examines the potential role of financing Africa's infrastructure projects with bonds indexed to the project. Developing a nation's infrastructure requires massive capital infusion, which the private sector is reluctant to commit to in the long run. However, capital markets have the depth, maturity, size and the capability of handling complex shocks and therefore have the potential of funding infrastructure projects. Hence, a nation can rely on the bond market to raise the capital which it needs to finance infrastructure projects. This would ensure diversification of financial risks and allocative efficiency.

Using option-pricing techniques, the paper shows that an infrastructure indexed bond is equivalent to a regular bond and a short position on a European put option. The results of the paper indicate that the value of the infrastructure indexed bond increases monotonically as the value of the project it is financing rise. Moreover, the market value of the infrastructure-indexed bonds falls as the value of the project becomes more volatile. The rise in the dividend rate on the project is observed to have an adverse effect on the value of infrastructure-indexed bonds.

\section{Acknowledgements}

The author would like to acknowledge the useful comments of colleagues at the Economic Commission for Africa. However, any errors or omissions must be attributed to the author. Of course, the views expressed in this paper are those of the authors and should not be attributed to the United Nations.

\section{References}

[1] Atta-Mensah, J. (1992) The Valuation of Commodity-Linked Bonds. Unpublished PhD Thesis, Simon Fraser University.

[2] Merton, R. (1973) The Theory of Rational Option Pricing. Bell Journal of Economics and Management Science, 4, 141-183. http://dx.doi.org/10.2307/3003143

[3] Merton, R. (1977) An Analytical Derivation of the Cost of Deposit Insurance and loan Guarantees: An Application of Modern Option Pricing Theory. Journal of Banking and Finance, 1, 3-11. http://dx.doi.org/10.1016/0378-4266(77)90015-2

[4] Geske, R. (1979) The Valuation of Compound Options. Journal of Financial Economics, 7, 63-81. http://dx.doi.org/10.1016/0304-405X(79)90022-9

[5] Gómez-Valle, L. and Martínez-Rodríguez, J. (2011) Advances in Pricing Commodity Futures: Multifactor Models. Mathematical and Computer Modelling, 57, 1722-1731.

[6] Bodie, Z., Kane, A. and Marcus, A.J. (2008) Essentials of Investments. McGraw-Hill, New York.

[7] Cvitanic, J. and Zapatero, F. (2004) Introduction to the Economics and Mathematics of Financial Markets. MIT Press, Cambridge, MA. 